\title{
Proton Pump Inhibitors Inhibit PHOSPHO1 Activity and Matrix Mineralisation In Vitro
}

\author{
Katherine A. Staines ${ }^{1}$ (I) $\cdot$ Katherine Myers ${ }^{2} \cdot$ Kirsty Little $^{2} \cdot$ Stuart H. Ralston ${ }^{3} \cdot$ Colin Farquharson $^{2}$
}

Received: 29 April 2021 / Accepted: 19 June 2021 / Published online: 2 July 2021

(c) The Author(s) 2021

\begin{abstract}
Proton pump inhibitors (PPIs) have been associated with an increased risk of fragility fractures in pharmaco-epidemiological studies. The mechanism is unclear, but it has been speculated that by neutralising gastric acid, they may reduce intestinal calcium absorption, causing secondary hyperparathyroidism and bone loss. Here we investigated that hypothesis that the skeletal effects of PPI might be mediated by inhibitory effects on the bone-specific phosphatase PHOSPHO1. We found that the all PPIs tested inhibited the activity of PHOSPHO1 with IC50 ranging between $0.73 \mu \mathrm{M}$ for esomeprazole to $19.27 \mu \mathrm{M}$ for pantoprazole. In contrast, these PPIs did not inhibit TNAP activity. We also found that mineralisation of bone matrix in primary osteoblast cultures was inhibited by several PPIs in a concentration dependent manner. In contrast, the histamine-2 receptor antagonists (H2RA) nizatidine, famotidine, cimetidine and ranitidine had no inhibitory effects on PHOSPHO1 activity. Our experiments show for the first time that PPIs inhibit PHOSPHO1 activity and matrix mineralisation in vitro revealing a potential mechanism by which these widely used drugs are associated with the risk of fractures.
\end{abstract}

Keywords PHOSPHO1 $\cdot$ Proton pump inhibitors $\cdot$ Histamine-2 receptor antagonists $\cdot$ Mineralisation $\cdot$ TNAP

\section{Introduction}

Proton pump inhibitors (PPIs) are amongst the most commonly prescribed drugs and are used in the treatment of gastroesophageal reflux disease (GORD), peptic ulcer disease and dyspepsia [1]. In the UK alone, more than 60 million PPI prescriptions were issued during 2017 [2]. The safety records of PPI's are generally favourable, but pharmacoepidemiological evidence has consistently shown a positive association between PPI use and bone fractures. For example, large scale studies conducted in Denmark, UK and Canada all reported an increased risk of osteoporosis related fractures including fractures to the hip and spine with chronic PPI therapy [3-5].

Katherine A. Staines

k.staines@ brighton.ac.uk

1 School of Pharmacy and Biomolecular Sciences, University of Brighton, Lewes Road, Brighton BN2 4GJ, UK

2 The Roslin Institute, The University of Edinburgh, Edinburgh, UK

3 Centre for Genomic and Experimental Medicine, Institute of Genetics and Cancer, University of Edinburgh, Edinburgh, UK
The most commonly accepted explanation is that PPIs predispose to fractures by neutralising gastric acid. This in turn is thought to impair intestinal calcium absorption, secondary hyperparathyroidism and increased osteoclastic bone resorption with bone loss [6-8]. However, in healthy subjects, short-term treatment with the PPI omeprazole was not found to have inhibitory effects on calcium absorption $[9,10]$. Furthermore, epidemiological studies with histamine 2 receptor antagonists (H2RAs), which also supress gastric acid secretion, have not shown an association with fractures [3,11-15]. Likewise, a recent meta-analysis reported that the use of PPIs, but not H2RAs, is associated with an increased risk of hip fracture [16]. These conflicting data suggest that PPI use may increase fracture incidence by a mechanism that distinct from effects on intestinal calcium absorption.

PHOSPHO1, a member of the haloacid dehalogenase superfamily, is a cytosolic phosphatase highly expressed by osteoblasts which is essential for bone mineralisation [17]. It liberates inorganic phosphate $\left(\mathrm{P}_{\mathrm{i}}\right)$ through the hydrolysis of phospholipid substrates within the matrix vesicle (MV) membrane [17-19]. Within this protected environment, $\mathrm{Pi}$ accumulates and chelates with $\mathrm{Ca}^{2+}$ which is enriched in MVs to form mineral crystals which subsequently invade 
and mineralise the organic collagenous scaffold [17-22]. Deletion of PHOSPHO1 in mice results in bowed long bones and spontaneous greenstick fractures, decreased cortical BMD and accumulation of osteoid in trabecular bone [23]. Similarly, osteoblasts treated with a PHOSPHO1specific inhibitor and cultures of Phosphol deficient primary osteoblast both revealed reduced matrix mineralising ability, whereas matrix mineralisation was increased by osteoblasts overexpressing PHOSPHO1 [24, 25]. A critical role for PHOSPHO1 in the mineralisation process was confirmed in a comparison of the bone phenotype of; $\mathrm{Alpl}^{-/-}$; Phosphol $^{-/-}$double knockout mice to that of $\mathrm{Alpl}^{-/-}$and Phosphol ${ }^{-1}$ mice. The skeleton of both single gene knockouts was impaired, whereas the double ablation led to the complete absence of skeletal mineralisation and embryonic lethality. These experimental data are consistent with the notion that PHOSPHO1 and TNAP have independent, nonredundant roles during the mineralisation process [23].

We previously identified, through a screen of chemical libraries containing over 50,000 compounds, the PPI, lansoprazole as a PHOSPHO1-specific inhibitor [18]. Indeed, lansoprazole non-competitively inhibited recombinant human PHOSPHO1 activity by over $70 \%$ and caused a $57 \%$ inhibition of osteoblast MV calcification, but had no effect on tissue non-specific alkaline phosphatase (TNAP) activity [18]. Furthermore, in vivo studies disclosed that lansoprazole administration to developing chick embryos completely inhibited mineralisation of all leg and wing long bones [26].

Considering the fact that PHOSPHO1 plays a critical role in bone mineralisation, we hypothesise that the association between PPI use and bone fractures is possibly due to their inhibitory effect on PHOSPHO1 activity. To address this hypothesis, we used in vitro approaches to evaluate the potential of commonly prescribed PPIs and H2RAs to inhibit both PHOSPHO1 enzyme activity and osteoblast matrix mineralisation.

\section{Materials and Methods}

\section{PPI and H2RAs}

The PPIs lansoprazole, omeprazole, pantoprazole and esomeprazole (Cayman Chemicals, Michigan, USA) were used at varying concentrations $(0-100 \mu \mathrm{M})$ in the phosphatase activity and in vitro mineralisation assays detailed below. Similarly, the H2RAs nizatidine, famotidine, cimetidine and ranitidine (Selleckchem, Munich, Germany) were also used at $0-100 \mu \mathrm{M}$.

\section{Primary Osteoblast Isolation}

Primary calvarial osteoblasts were obtained from 4-day-old wild-type C57B1/6 mice. Primary osteoblasts were isolated by sequential enzyme digestion of excised calvarial bones using a four-step process as has previously been described [7, 8] [1 mg/ml collagenase type II in Hanks' balanced salt solution (HBSS) for $10 \mathrm{~min} ; 1 \mathrm{mg} / \mathrm{ml}$ collagenase type II in HBSS for $30 \mathrm{~min}$; $4 \mathrm{mM}$ EDTA for $10 \mathrm{~min} ; 1 \mathrm{mg} / \mathrm{ml}$ collagenase type II in HBSS for $30 \mathrm{~min}]$. The first digest was discarded and the cells were re-suspended in growth medium consisting of a-MEM (Invitrogen, Paisley, UK) supplemented with $10 \%$ (v/v) FBS and $1 \%$ gentamycin (Invitrogen). Osteoblasts were seeded at a density of $1 \times 10^{4}$ cells $/ \mathrm{cm}^{2}$ and grown to confluency at which point $2 \mathrm{mM}$ $\beta$-glycerophosphate and $50 \mu \mathrm{g} / \mathrm{ml}$ ascorbic acid was added along with a PPI $(0-50 \mu \mathrm{M})$ as described in the results. Media was changed every 2-3 days for the duration of the 28-day experiments.

\section{Assessment of Primary Osteoblast Matrix Mineralisation}

After 28 days, primary cell cultures were fixed in 4\% paraformaldehyde for $5 \mathrm{~min}$ at room temperature. Cell monolayers were stained with aqueous $2 \%(\mathrm{w} / \mathrm{v})$ Alizarin red solution for $5 \mathrm{~min}$ at room temperature. The bound stain was solubilised in $10 \%$ cetylpyridinium chloride and the optical density of the resultant eluted solution measured by spectrophotometry at $570 \mathrm{~nm}$.

\section{Phosphatase Assays}

Recombinant human PHOSPHO1 (50 ng) was generated as previously described [27] and incubated with varying concentrations of the aforementioned PPIs and H2RAs in experimental assay buffer ( $20 \mathrm{mM}$ Tris, $2 \mathrm{mM} \mathrm{MgCl} \& 25 \mu \mathrm{g} /$ $\mathrm{ml} \mathrm{BSA}$ ) at $37^{\circ} \mathrm{C}$ for $15 \mathrm{~min}$. Using the BIOMOL® Green assay (Enzo, Exeter, UK), standards (0-2 nM) and samples were then incubated with $2.5 \mathrm{mM} \beta$-glycerol phosphate for $30 \mathrm{~min}$ at $37^{\circ} \mathrm{C}$ with gentle agitation [27]. The reaction was stopped using $100 \mu \mathrm{l}$ BIOMOL® Green and after being left for $30 \mathrm{~min}$ at room temperature, the absorbance was read using spectrophotometry at $630 \mathrm{~nm}$. For TNAP, $2 \mathrm{ng}$ recombinant human TNAP (R\&D Systems, Abington, UK), was incubated with varying concentrations of the aforementioned PPIs and H2RAs in experimental assay buffer (1 M diethylamine hydrochloride, $1 \mathrm{mM} \mathrm{MgCl}{ }_{2}$ and $20 \mu \mathrm{M} \mathrm{ZnCl}_{2}$ ). Using the BIOMOL $®$ Green assay, standards $(0-2 \mathrm{nM})$ and samples were then incubated with $0.5 \mathrm{mM}$ p-nitrophenyl phosphate (pNPP) for $30 \mathrm{~min}$ at $37^{\circ} \mathrm{C}$ with gentle agitation. 
The reaction was stopped using $100 \mu \mathrm{l}$ BIOMOL® Green and after being left for $30 \mathrm{~min}$ at room temperature, the absorbance was read using spectrophotometry at $630 \mathrm{~nm}$.

\section{Statistical Analysis}

The data are expressed as the mean \pm standard error of the mean (S.E.M) of at least three independent experiments. Statistical analysis was performed by one-way analysis of variance (ANOVA). $P<0.05$ was considered to be significant and noted as *; $P$ values of $<0.01$ and $<0.001$ were noted as ' $* *$ ' and '***' respectively.

\section{Results}

\section{PPIs are Potent Inhibitors of PHOSPHO1 Activity}

In accordance with our previous results, lansoprazole inhibited PHOSPHO1 activity $\left(\mathrm{IC}_{50}=2.767 \mu \mathrm{M}\right.$; Fig. 1A). Similarly, here we show for the first time that the PPIs omeprazole

A

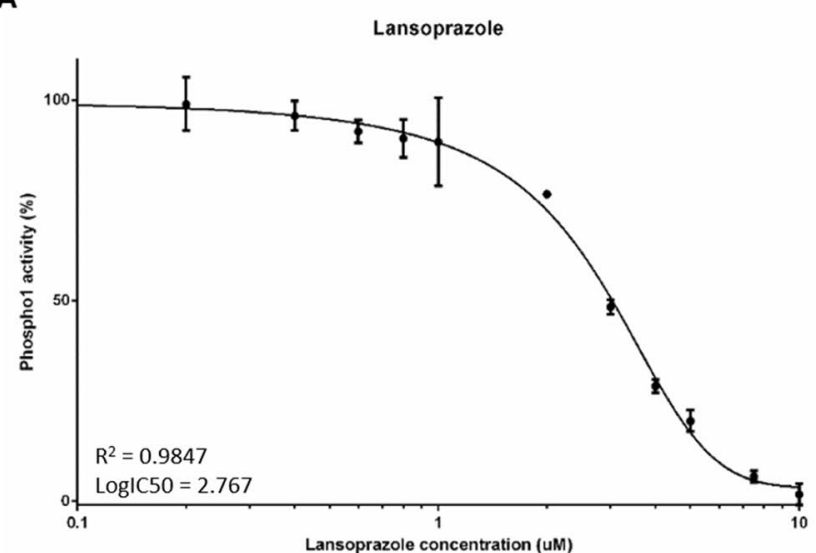

C

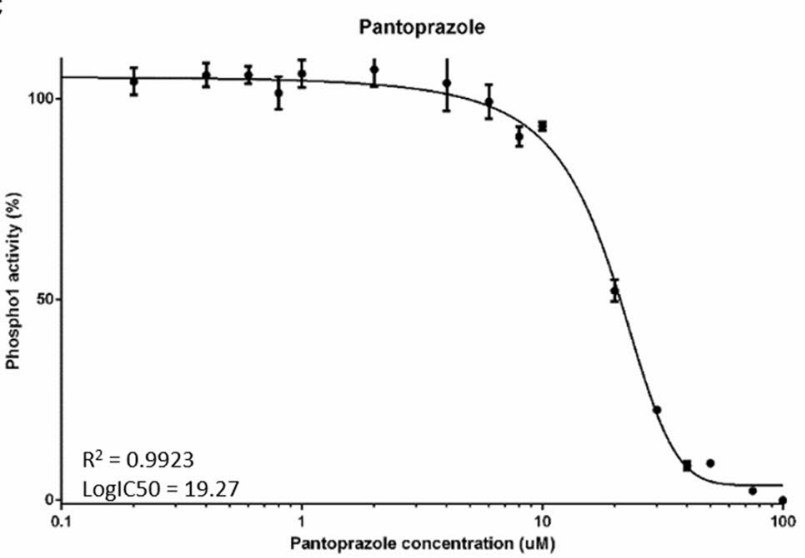

$\left(\mathrm{IC}_{50}=2.803 \mu \mathrm{M}\right)$ and esomeprazole $\left(\mathrm{IC}_{50}=0.726 \mu \mathrm{M}\right)$ are potent inhibitors of PHOSPHO1 activity (Fig. 1B, C). Whilst pantoprazole also inhibited PHOSPHO1 activity, its $\mathrm{IC}_{50}$ was $19.27 \mu \mathrm{M}$, suggesting that this PPI is the least potent PHOSPHO1 inhibitor tested (Fig. 1D).

\section{PHOSPHO1 Activity is Not Inhibited by H2RAs}

We next sought to examine whether PHOSPHO1 activity is similarly inhibited by four commonly prescribed H2RAs. At all concentrations tested, there was no inhibition of PHOSPHO1 activity upon addition of nizatidine (Fig. 2A), famotidine (Fig. 2B), cimetidine (Fig. 2C) and ranitidine (Fig. 2D).

\section{PPIs and H2RAs Have No Effect on TNAP Activity}

We next determined whether the aforementioned PPIs are able to inhibit TNAP activity. At all concentrations tested, lansoprazole, omeprazole, esomeprazole and pantoprazole did not inhibit TNAP activity (Fig. 3A-D). Similarly,

B

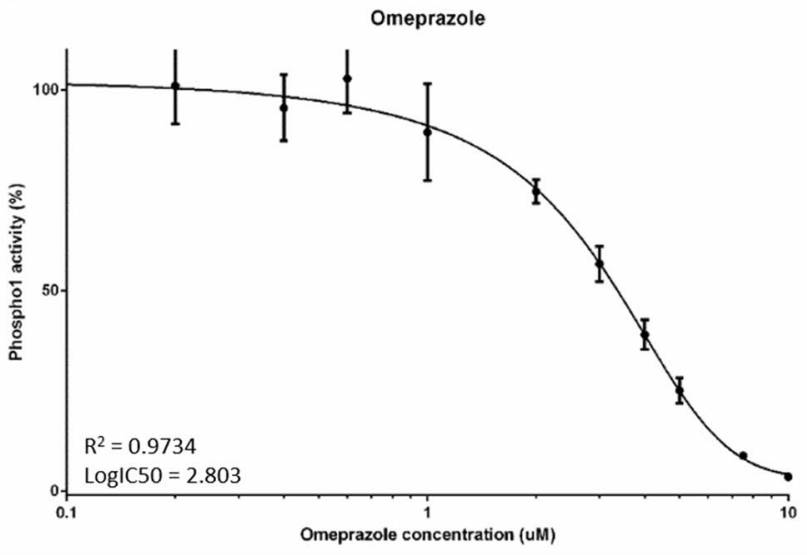

D

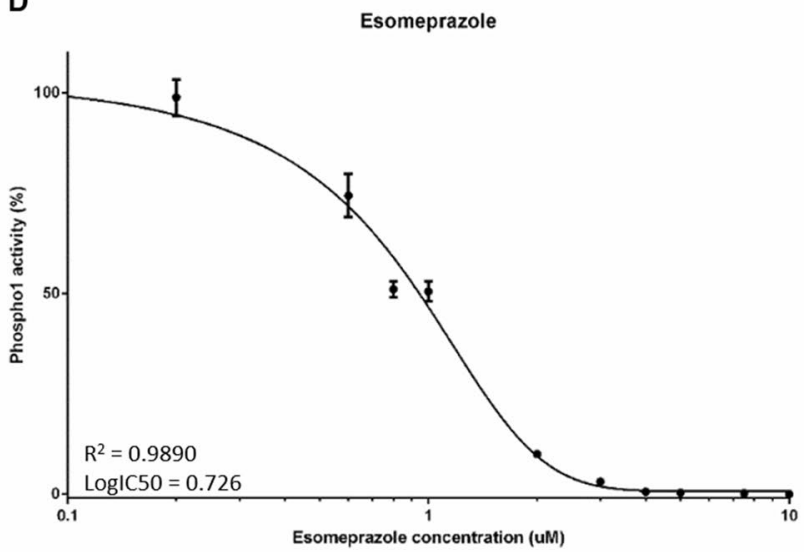

Fig. 1 The effects of proton pump inhibitors (PPIs) on PHOSPHO1 activity. PHOSPHO1 activity was assessed by phosphatase assays in the presence of A lansoprazole, B omeprazole, $\mathbf{C}$ esomeprazole and $\mathbf{D}$ pantoprazole 
A

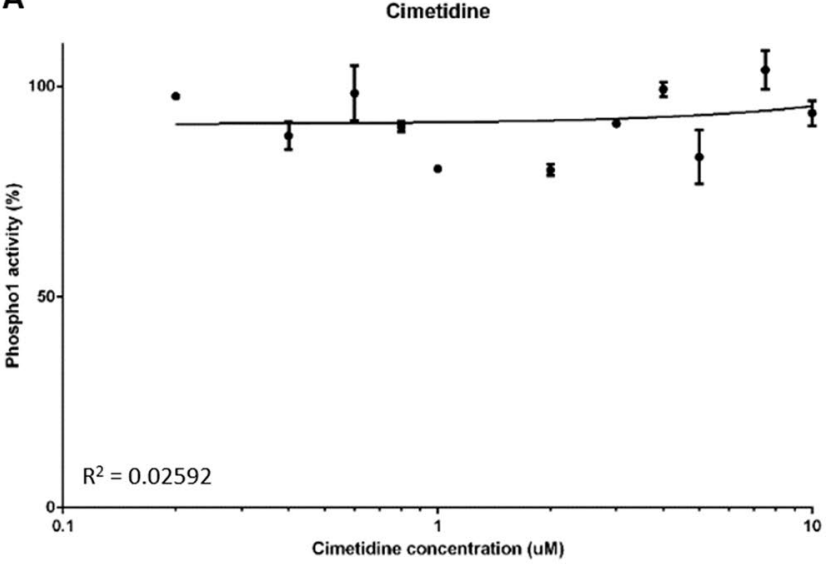

C

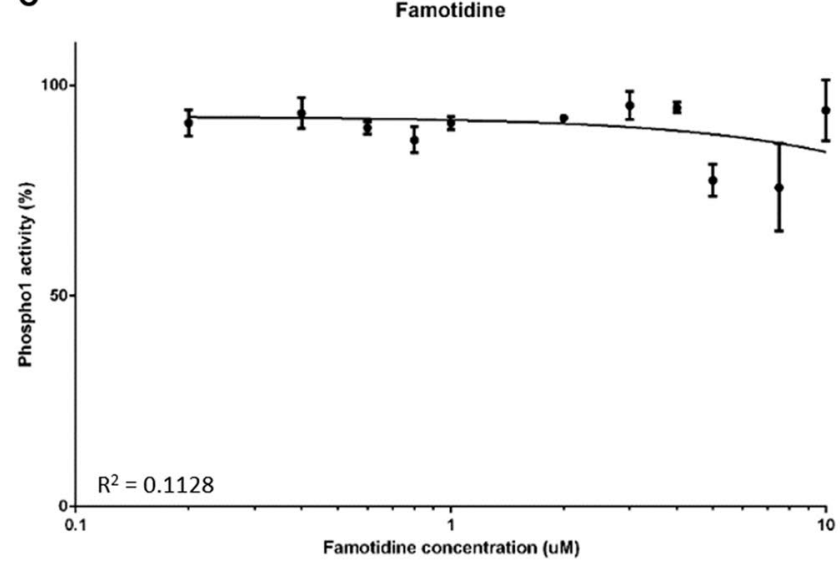

B

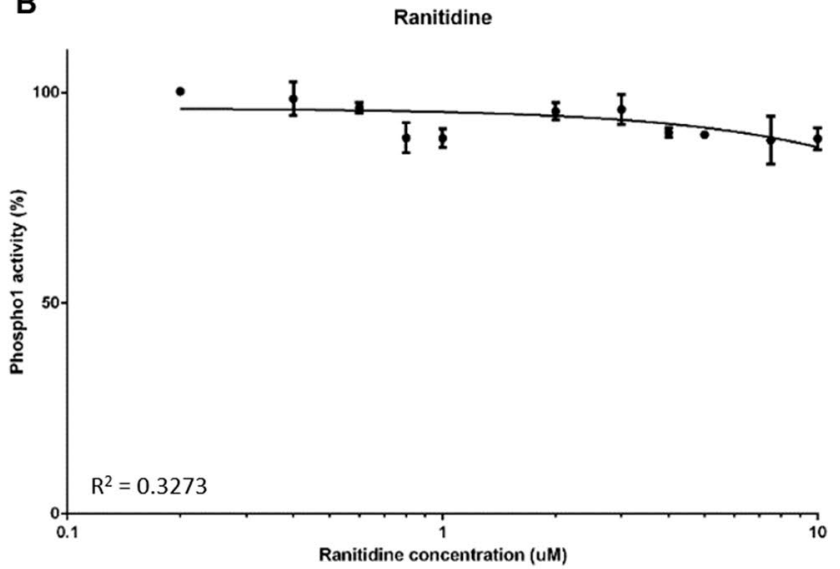

D

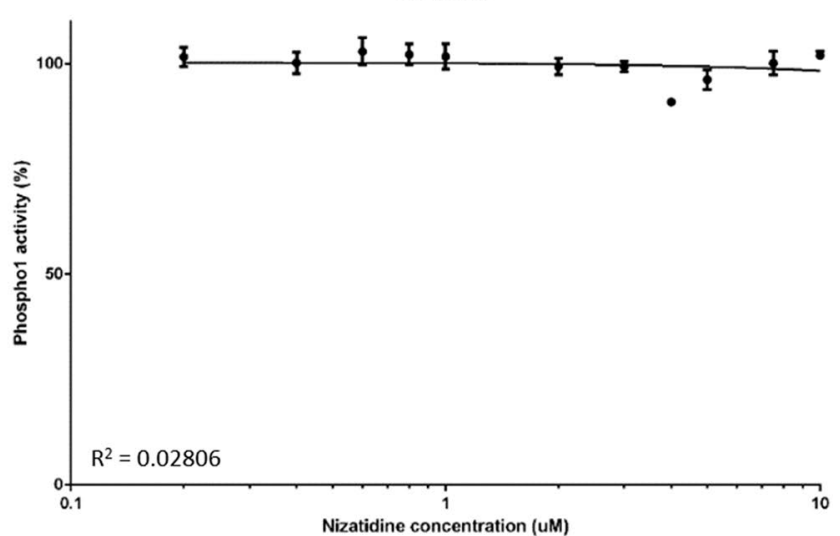

Fig. 2 The effects of histamine-2 receptor antagonists (H2RAs) on PHOSPHO1 activity. PHOSPHO1 activity was assessed by phosphatase assays in the presence of $\mathbf{A}$ cimetidine, $\mathbf{B}$ ranitidine, $\mathbf{C}$ famotidine and $\mathbf{D}$ nizatidine

there was no inhibition of TNAP activity by the H2RAs (Fig. 4A-D).

\section{PP1s Inhibit Primary Osteoblast Matrix Mineralisation}

To examine whether the inhibition of PHOSPHO1 by PPIs has an effect on matrix mineralisation, we cultured primary osteoblasts in the presence of different concentrations of lansoprazole, omeprazole, esomeprazole and pantoprazole. We found that whilst control cultures formed mineralised nodules after 28 days in culture, the addition of $5 \mu \mathrm{M}$ and $10 \mu \mathrm{M}$ lansoprazole significantly decreased matrix mineralisation (Fig. 5A-C). Despite this, nodules were clearly visible throughout the cultures suggestive that collagen deposition is still occurring and therefore the effects seen are directly on the mineralisation of this matrix (Fig. 5A). Similarly, omeprazole and esomeprazole significantly inhibited matrix mineralisation at concentration of $10 \mu \mathrm{M}$ (Fig. 5A-C). In concordance with the higher $\mathrm{IC}_{50}$ of pantoprazole, culture of primary osteoblasts with $5 \mu \mathrm{M}$ and $10 \mu \mathrm{M}$ pantoprazole was not sufficient to inhibit matrix mineralisation (Fig. 5A-C). We therefore cultured cells with $50 \mu \mathrm{M}$ pantoprazole and indeed saw a significant decrease in matrix mineralisation (Fig. 5D).

\section{Discussion}

In this study, we report that all the PPIs tested were inhibitors of PHOSPHO1 activity whilst they had no effect on TNAP activity. The most potent inhibitor was esomeprazole which gave $50 \%$ inhibition in the sub-micromolar range, followed by lansoprazole, omeprazole and pantoprazole Consistent with this, the PPIs we tested inhibited mineralisation of bone matrix in vitro in low micromolar concentrations, except pantoprazole which did not have inhibitory effects until higher concentrations of 50uM were used. Conversely, we tested several H2RAs and these had no effect on PHOSPHO1 or TNAP phosphatase activity. 
A

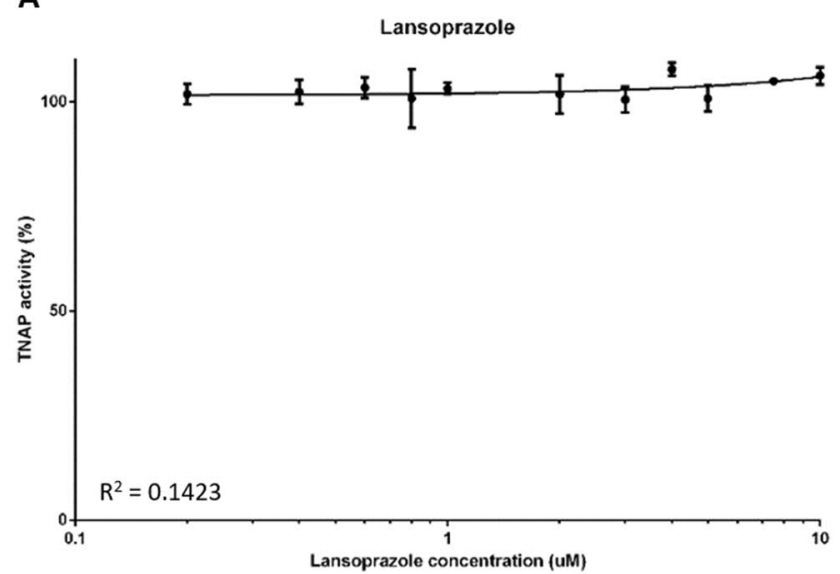

C

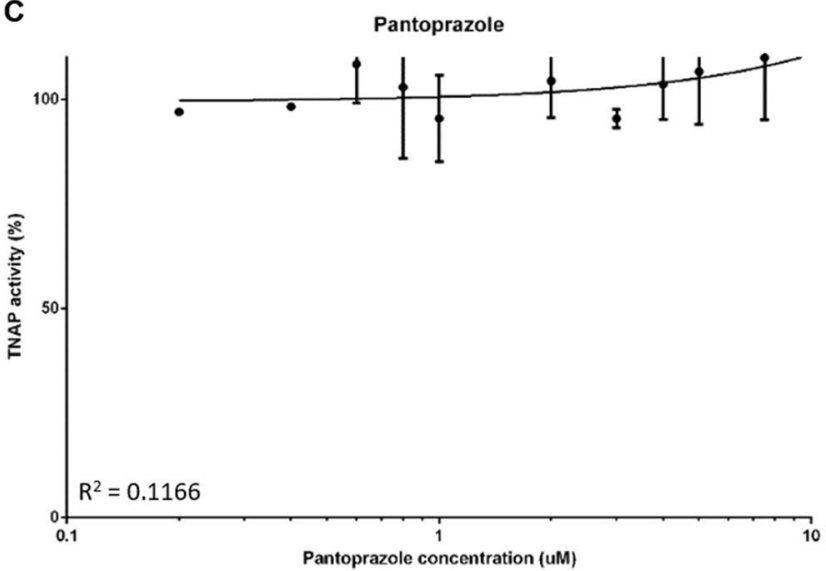

B

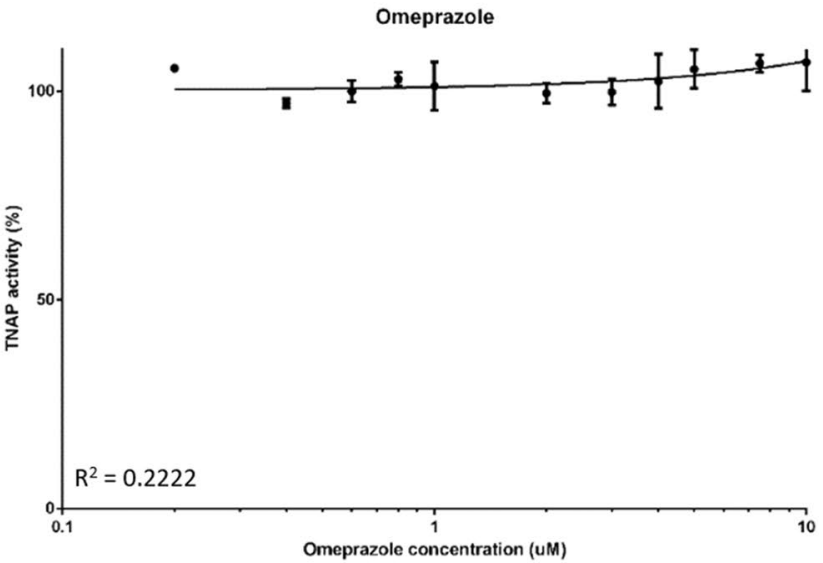

D

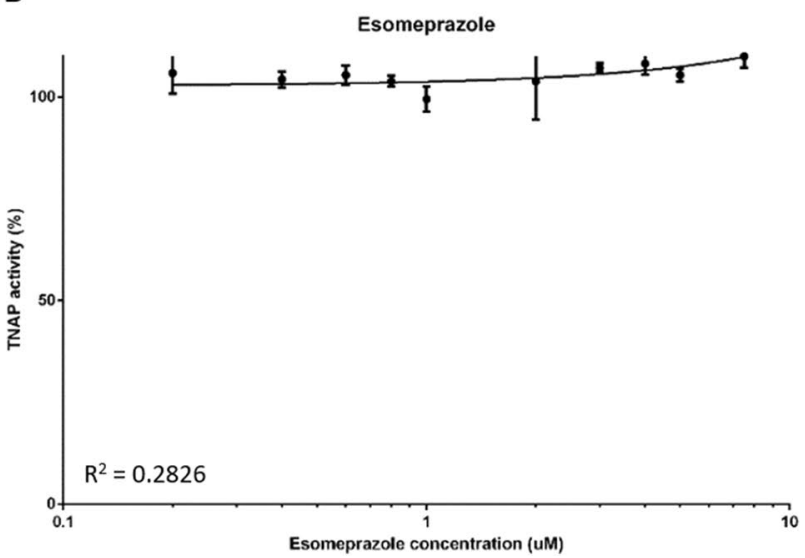

Fig. 3 The effects of proton pump inhibitors (PPIs) on TNAP activity. TNAP activity was assessed by phosphatase assays in the presence of the PPIs A lansoprazole, $\mathbf{B}$ omeprazole, $\mathbf{C}$ esomeprazole and $\mathbf{D}$ pantoprazole

Several studies have shown an association with between PPIs use and fractures. Indeed, a large-scale meta-analysis has reported a significant increase in relative risk (RR) of fractures at the hip $[\mathrm{RR}=1.26,95 \% \mathrm{CI}=1.16-1.36]$ spine $[\mathrm{RR}=1.58,95 \% \mathrm{CI}=1.38-1.82]$ and any-site fractures $[\mathrm{RR}=1.33,95 \% \mathrm{CI}=1.15-1.54]$ in PPI users as compared to controls [28].

The PPIs reduce gastric acid secretion through inhibition of $\mathrm{H}+/ \mathrm{K}+-$ ATPases located in stomach parietal cells [29]. In view of this it has been speculated that calcium malabsorption mediated by neutralisation of gastric acid may cause secondary hyperparathyroidism and bone loss [6-8]. Other potential mechanisms include (i) impaired bone resorption resulting in altered bone remodelling and (ii) hypergastrinemia resulting in parathyroid hyperplasia and decreased bone mineral density [30, 31]. The H2RAs are also widely used to suppress gastric acid production in the treatment of GORD, dyspepsia and peptic ulcers these have not been associated with fractures in epidemiological studies which calls into question the hypothesis that the association between fractures and PPI used is mediated by reduced calcium absorption due to achlorhydria $[3,11-15]$. The data presented here is consistent with this and suggests that inhibition of PHOSPO1 may be an alternative mechanism by which PPIs, affect bone health. The PHOSPHO1 enzyme is a bone-specific phosphatase that is highly expressed at sites of mineralization and essential for the formation of mechanically competent bone [17]. It is biochemically active within MVs [18] and it has been proposed that the accumulation of $\mathrm{Pi}$ within MVs is a consequence of PHOSPHO1s intravesicular activity and also intravesicular trafficking of TNAP-generated Pi via a Type III Na-Pi co-transporter, PiT1 [32-34]. We have previously shown that MV mineralisation is reduced in Phosphol $^{-/-}$mice $[33,35]$ and that lansoprazole treatment of MVs isolated from osteoblasts impairs their mineralisation [26]. It is therefore possible that PPI inhibition of PHOSPHO1 activity disrupts the biochemical machinery needed to establish the appropriate inorganic pyrophosphate to $\mathrm{Pi}$ ratio required to initiate the formation of HA 
A

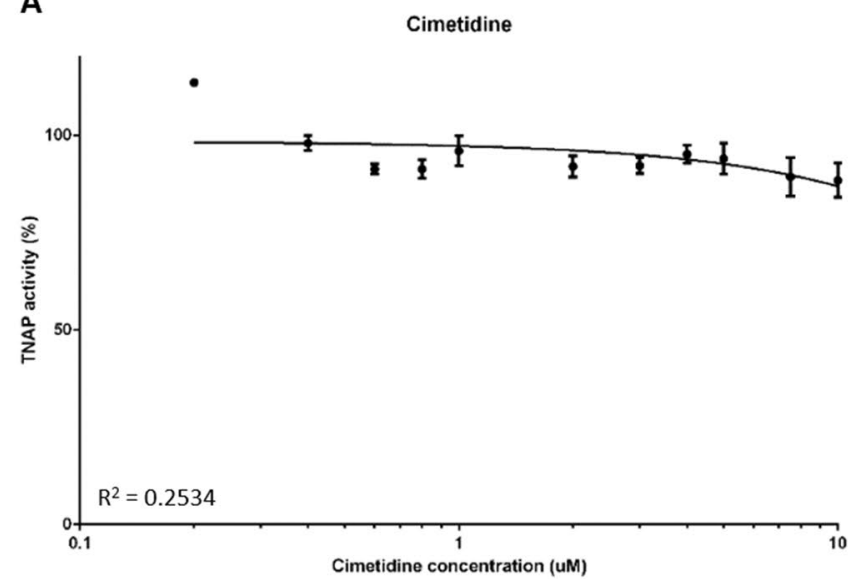

C

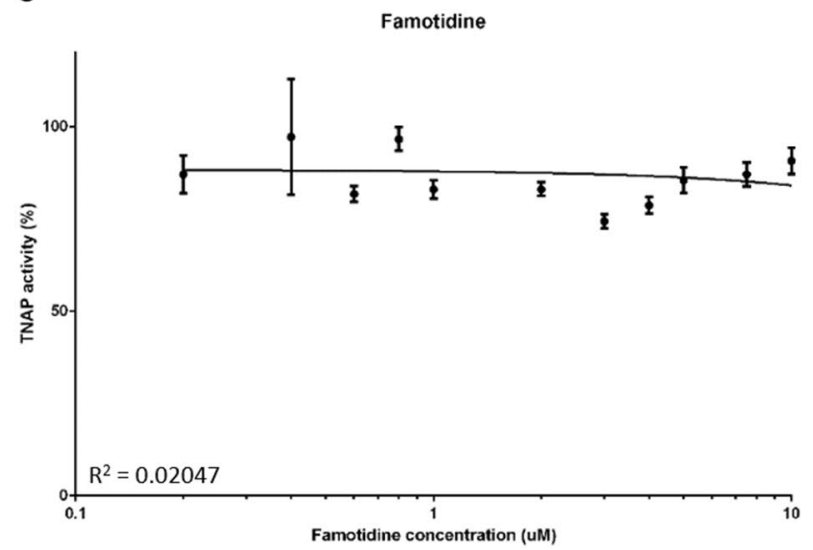

B

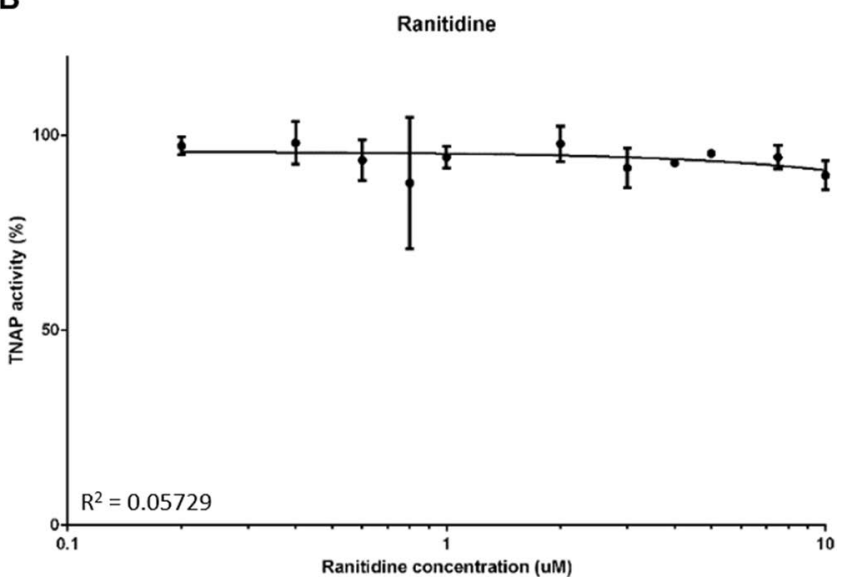

D

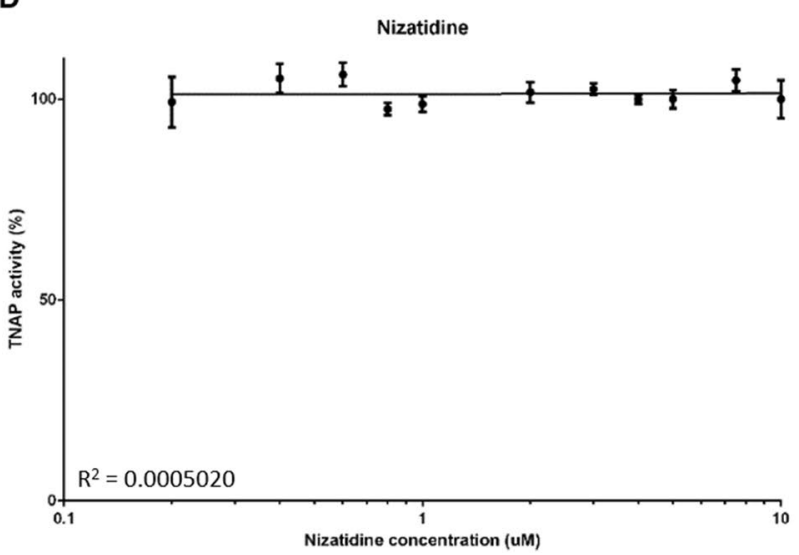

Fig. 4 The effects of histamine-2 receptor antagonists (H2RAs) on TNAP activity. TNAP activity was assessed by phosphatase assays in the presence of the H2RAs A cimetidine, $\mathbf{B}$ ranitidine, $\mathbf{C}$ famitidine and $\mathbf{D}$ nizatidine

mineral within MVs $[34,36]$. Our in vitro cell culture work is also consistent with a previous study in which lansoprazole, esomeprazole and omeprazole decreased the ability of osteoblasts to mineralise their matrix, whilst also inhibiting osteoblast gene expression [37]. Therefore, it is plausible that the PPIs could also be having a negative effect on osteoblast differentiation and so to ensure that the mineralisation inhibitory effects observed here are solely due to PHOSPHO1 inhibition, it would be expected that the PPIs would exert the same effect if they were added only to the latter stages of the culture period, rather than throughout. However, we saw no effect on nodule formation, suggesting that our osteoblast cultures are still producing a collagenous matrix and it is indeed the mineralisation of this matrix which is being inhibited. These observations at the cell and MV level are consistent with, and explain, the reduced bone mineral content and BMD in rodents administered omeprazole [38, 39].

Interestingly, the data of this present study indicated no effect of PPIs on TNAP phosphatase activity; a result that is consistent with our previous study that reported lansoprazole and other small molecule inhibitors of PHOSPHO1 had no effect on TNAP activity [18]. The importance of TNAP in the mineralisation process is well accepted [40, 41]. Indeed, in patients with hypophosphatasia and also in $\mathrm{Alpl}^{-/-}$mice, extravesicular crystal propagation is retarded due to an accumulation of inorganic pyrophosphate in the extracellular matrix [42]. These data imply that the inhibition of osteoblast matrix mineralisation by the PPIs is via their inhibition of PHOSPHO1, and not TNAP activity. A note of caution in the interpretation of these data is nevertheless warranted; other in vitro studies have reported that lansoprazole can inhibit porcine TNAP activity albeit with a Ki value of $\sim 100$ times higher than that reported for the inhibition of recombinant human PHOSPHO1 with lansoprazole [18, 43]. An explanation for these different results is unclear.

We have previously shown TNAP expression and activity to be decreased in PHOSPHO1 knockout osteoblasts, with a concomitant increase in inorganic pyrophosphate levels [23]. However, the contribution of lowered TNAP levels to the decreased mineralisation noted in the absence of PHOSPHO1 is debatable, as transgenic overexpression of TNAP 
A
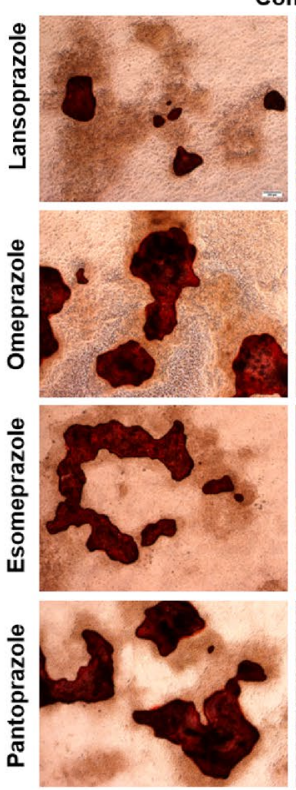

Control
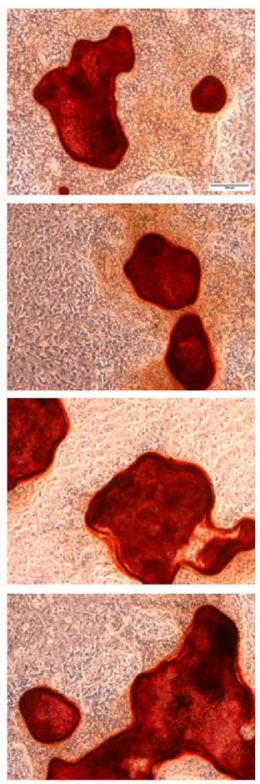

$5 \mu \mathrm{M}$
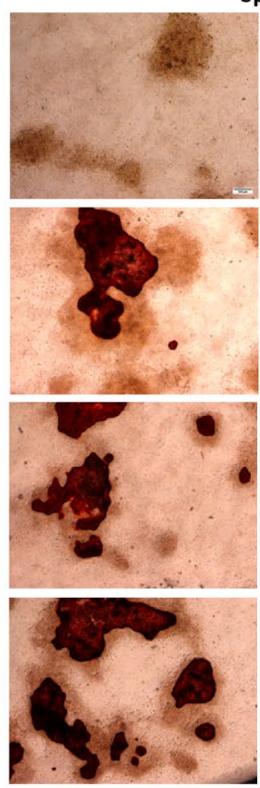
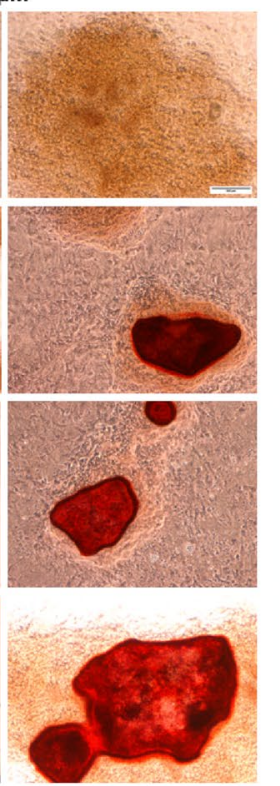

$10 \mu \mathrm{M}$
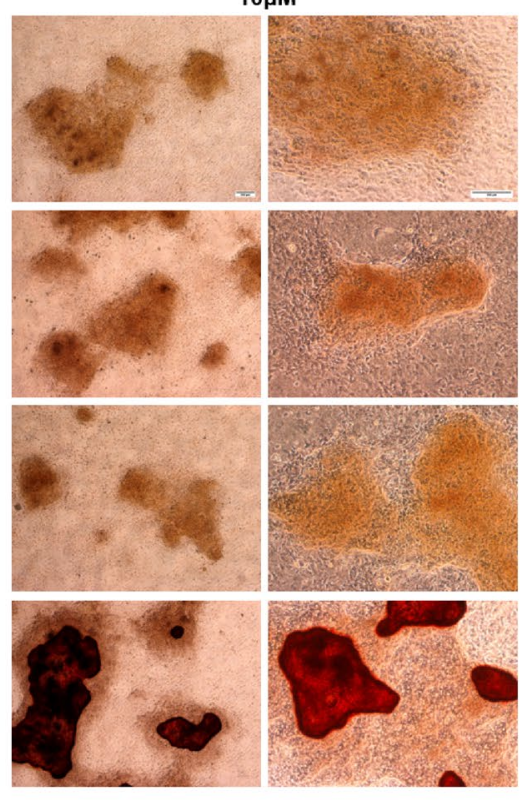

B
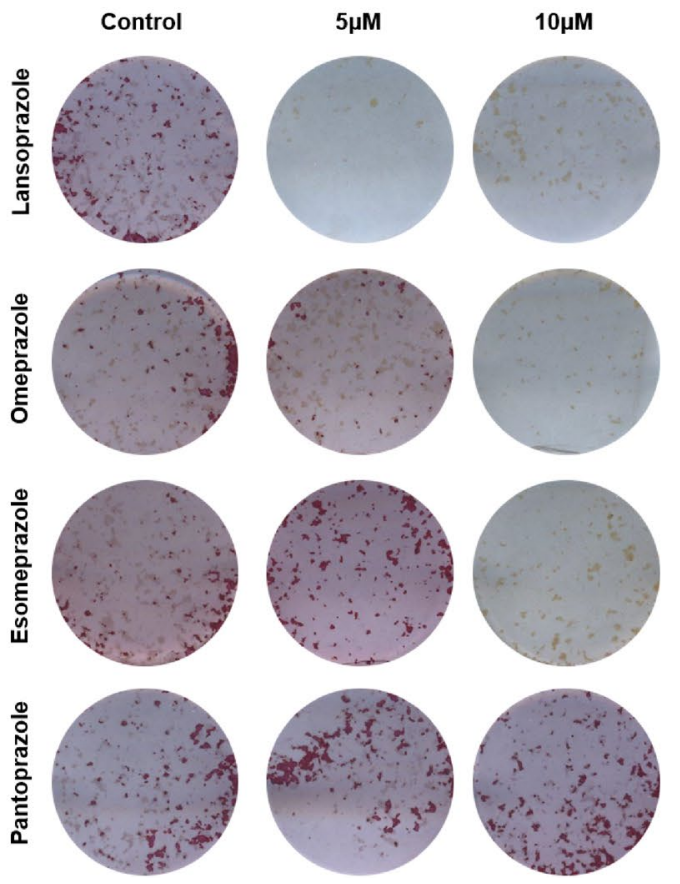

Fig. 5 The effects of proton pump inhibitors (PPIs) on primary osteoblast matrix mineralisation. Primary osteoblasts were cultured for 28 days in the presence of $0-10 \mu \mathrm{M}$ lansoprazole, omeprazole, esomeprazole and pantoprazole. A Microscopic images of alizarin red stained mineral associated with nodule formation. Scale bars are

did not correct the bone hypomineralisation of Phospho1 knockout mice, despite normalisation of their plasma inorganic pyrophosphate levels [23]. Therefore, it is likely that the main cause of the hypomineralisation seen in our PPI treated cell cultures is indeed due to inhibition of PHOSPHO1 activity, as also indicated in our phosphatase assays.

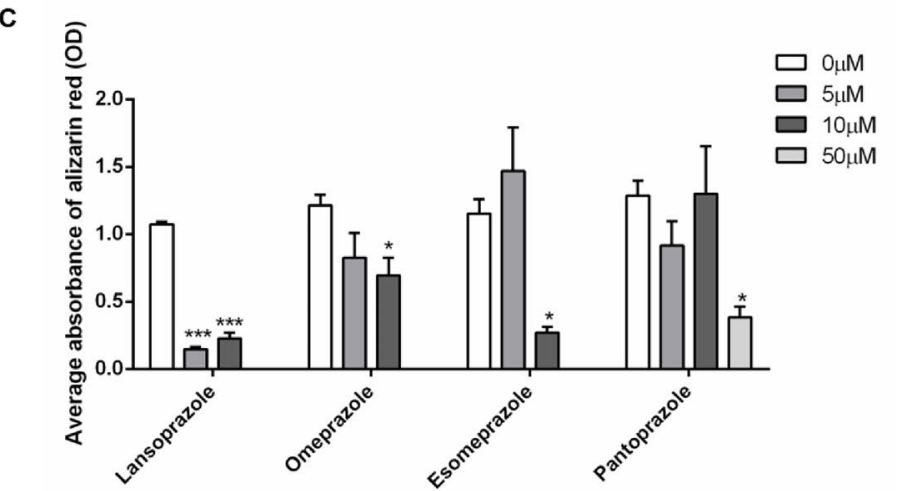

D

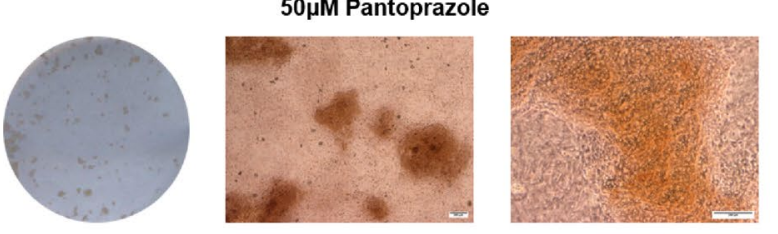

$200 \mu \mathrm{m}$. B Alizarin red staining. Images are representative of three individual experiments. C Quantification of alizarin red staining, D Alizarin red staining of primary osteoblasts treated with $50 \mu \mathrm{M}$ pantoprazole. The data are represented as mean \pm S.E.M. $(n=3$ wells/ treatment) $P<0.05^{*}, P<0.01^{* *}, P<0.001^{* * *}$

The order of potency (based on our $\mathrm{IC}_{50}$ data) of PPI inhibition of PHOSPHO1 activity is esomeprazole $>$ omeprazole $=$ lansoprazole $>$ pantoprazole (Fig. 2), which precisely mimics our data in mineralising primary osteoblasts, but also their ability (based on omeprazole equivalents) to inhibit acid production $[44,45]$. Intriguingly, this suggests 
that the structure of the more potent acid suppressive PPIs accounts for their PHOSPHO1 inhibitory properties. Also, pantoprazole, the PPI least able to inhibit PHOSPHO1 enzyme activity was also a poor inhibitor of matrix mineralisation. Knowing the molecular model of PHOSPHO1 [21], it would be of interest to perform ligand docking studies to gain more information as to how the different PPIs associate with the enzyme and temper its biological activity. This has the potential to equip industry with the knowledge to generate modified and improved PPIs without the undesired off target bone effects.

In summary, we have shown that commonly prescribed PPIs, but not H2RAs, inhibit the activity of the bonespecific phosphatase, PHOSPHO1 in vitro in a dosedependent manner and at concentrations that are similar to those used clinically. We have also shown that different PPIs differ by more than 25 -fold in their ability to inhibit PHOSPHO1 activity when compared with a sevenfold difference in potency for inhibition of acid production [44]. This indicates that there is a $>$ threefold difference in the ability of PPIs to inhibit PHOSPHO1 activity as compared with their ability to suppress gastric acid production.

Considering the fact that PHOSPHO1 plays a critical role in bone mineralisation, we hypothesise that the association between PPI use and bone fractures is possibly due to their inhibitory effect on PHOSPHO1 activity. Although this remains to be confirmed by further research it could have clinical implications in allowing clinicians to select PPIs with the least inhibitory effect on PHOSPHO1 activity as the preferred drug in this class in patients at high risk of fragility fractures.

Author Contributions Conception and design of the study: KS, SR, CF. Acquisition of data: KS, KM, KL. Interpretation of data: KS, CF. Drafting the manuscript: KS, CF. Revising the manuscript and final approval, and agreement to be accountable for all aspects of the work: all authors.

Funding We are grateful to Medical Research Scotland for a Vacation Scholarship (KM) and the Society for Endocrinology for a Summer Studentship (KL). We are also grateful to the Biotechnology and Biological Sciences Research Council (BBSRC) for Institute Strategic Programme Grant Funding BB/J004316/1.

Data Availability Data are available on reasonable request from the corresponding authors.

\section{Declarations}

Conflict of interest Katherine A. Staines, Katherine Myers, Kirsty Little, Stuart H. Ralston, Colin Farquharson state that they have no conflicts of interest.

Ethical Approval All experimental protocols were approved by Roslin Institute's Animal Users Committee and the animals were maintained in accordance with UK Home Office guidelines for the care and use of laboratory animals, and with the ARRIVE guidelines.

Informed Consent For this type of study, no informed consent is required.

Open Access This article is licensed under a Creative Commons Attribution 4.0 International License, which permits use, sharing, adaptation, distribution and reproduction in any medium or format, as long as you give appropriate credit to the original author(s) and the source, provide a link to the Creative Commons licence, and indicate if changes were made. The images or other third party material in this article are included in the article's Creative Commons licence, unless indicated otherwise in a credit line to the material. If material is not included in the article's Creative Commons licence and your intended use is not permitted by statutory regulation or exceeds the permitted use, you will need to obtain permission directly from the copyright holder. To view a copy of this licence, visit http://creativecommons.org/licenses/by/4.0/.

\section{References}

1. Hollingworth S, Duncan EL, Martin JH (2010) Marked increase in proton pump inhibitors use in Australia. Pharmacoepidemiol Drug Saf 19:1019-1024. https://doi.org/10.1002/pds.1969

2. Prescription Cost Analysis - NHS Digital. https://digital.nhs.uk/ data-and-information/publications/statistical/prescription-costanalysis. Accessed 12 Mar 2021

3. Vestergaard P, Rejnmark L, Mosekilde L (2006) Proton pump inhibitors, histamine $\mathrm{H} 2$ receptor antagonists, and other antacid medications and the risk of fracture. Calcif Tissue Int 79:76-83. https://doi.org/10.1007/s00223-006-0021-7

4. Targownik LE, Lix LM, Metge CJ et al (2008) Use of proton pump inhibitors and risk of osteoporosis-related fractures. CMAJ 179:319-326. https://doi.org/10.1503/cmaj.071330

5. Yang YX, Lewis JD, Epstein S, Metz DC (2006) Long-term proton pump inhibitor therapy and risk of hip fracture. J Am Med Assoc 296:2947-2953. https://doi.org/10.1001/jama.296.24.2947

6. Hardy P, Sechet A, Hottelart C et al (1998) Inhibition of gastric secretion by omeprazole and efficiency of calcium carbonate on the control of hyperphosphatemia in patients on chronic hemodialysis. Artif Organs 22:569-573. https://doi.org/10.1046/j.15251594.1998.06200.x

7. Insogna KL (2009) The effect of proton pump-inhibiting drugs on mineral metabolism. Am J Gastroenterol 104:S2-4

8. O'Connell MB, Madden DM, Murray AM et al (2005) Effects of proton pump inhibitors on calcium carbonate absorption in women: a randomized crossover trial. Am J Med 118:778-781. https://doi.org/10.1016/j.amjmed.2005.02.007

9. Hansen KE, Jones AN, Lindstrom MJ et al (2010) Do proton pump inhibitors decrease calcium absorption? J Bone Miner Res 25:2786-2795. https://doi.org/10.1002/jbmr.166

10. Serfaty-Lacrosniere C, Wood RJ, Voytko D et al (1995) hypochlorhydria from short-term omeprazole treatment does not inhibit intestinal absorption of calcium, phosphorus, magnesium or zinc from food in humans. J Am Coll Nutr 14:364-368. https://doi.org/ 10.1080/07315724.1995.10718522

11. de Vries F, Cooper AL, Cockle SM et al (2009) Fracture risk in patients receiving acid-suppressant medication alone and in combination with bisphosphonates. Osteoporos Int 20:1989-1998. https://doi.org/10.1007/s00198-009-0891-4

12. Yu EW, Blackwell T, Ensrud KE et al (2008) Acid-suppressive medications and risk of bone loss and fracture in older 
adults. Calcif Tissue Int 83:251-259. https://doi.org/10.1007/ s00223-008-9170-1

13. Gray SL, Lacroix AZ, Larson J et al (2010) Proton pump inhibitor use, hip fracture, and change in bone mineral density in postmenopausal women: results from the women's health initiative. Arch Intern Med 170:765-771. https://doi.org/10.1001/archinternmed. 2010.94

14. Park JH, Lee J, Yu SY et al (2020) Comparing proton pump inhibitors with histamin-2 receptor blockers regarding the risk of osteoporotic fractures: a nested case-control study of more than 350,000 Korean patients with GERD and peptic ulcer disease. BMC Geriatr 20:407. https://doi.org/10.1186/s12877-020-01794-3

15. Lyu B, Hansen KE, Jorgenson MR, Astor BC (2020) Associations between proton pump inhibitor and histamine-2 receptor antagonist and bone mineral density among kidney transplant recipients. Am J Nephrol 51:433-441. https://doi.org/10.1159/000507470

16. Poly TN, Islam MM, Yang HC et al (2019) Proton pump inhibitors and risk of hip fracture: a meta-analysis of observational studies. Osteoporos Int 30:103-114. https://doi.org/10.1007/ s00198-018-4788-y

17. Dillon S, Staines KA, Millán JL, Farquharson C (2019) How to build a bone: PHOSPHO1, biomineralization, and beyond. JBMR Plus 3:e10202. https://doi.org/10.1002/jbm4.10202

18. Roberts S, Narisawa S, Harmey D et al (2007) Functional involvement of PHOSPHO1 in matrix vesicle-mediated skeletal mineralization. J Bone Miner Res 22:617-627. https://doi.org/10.1359/ jbmr.070108

19. Stewart AJ, Roberts SJ, Seawright E et al (2006) The presence of PHOSPHO1 in matrix vesicles and its developmental expression prior to skeletal mineralization. Bone 39:1000-1007. https://doi. org/10.1016/j.bone.2006.05.014

20. Houston B, Stewart AJ, Farquharson C (2004) PHOSPHO1-A novel phosphatase specifically expressed at sites of mineralisation in bone and cartilage. Bone 34:629-637. https://doi.org/10.1016/j. bone.2003.12.023

21. Stewart AJ, Schmid R, Blindauer CA et al (2003) Comparative modelling of human PHOSPHO1 reveals a new group of phosphatases within the haloacid dehalogenase superfamily. Protein Eng 16:889-895. https://doi.org/10.1093/protein/gzg126

22. Houston B, Seawright E, Jefferies D et al (1999) Identification and cloning of a novel phosphatase expressed at high levels in differentiating growth plate chondrocytes1. Biochim Biophys Acta-Mol Cell Res 1448:500-506. https://doi.org/10.1016/ S0167-4889(98)00153-0

23. Yadav MC, Simão AMS, Narisawa S et al (2011) Loss of skeletal mineralization by the simultaneous ablation of PHOSPHO1 and alkaline phosphatase function: a unified model of the mechanisms of initiation of skeletal calcification. J Bone Miner Res 26:286297. https://doi.org/10.1002/jbmr.195

24. Huesa C, Houston D, Kiffer-Moreira T et al (2015) The functional co-operativity of tissue-nonspecific alkaline phosphatase (TNAP) and PHOSPHO1 during initiation of skeletal mineralization. Biochemi Biophys Rep 4:196-201. https://doi.org/10.1016/j.bbrep. 2015.09.013

25. Javaheri B, Carriero A, Staines KA et al (2015) Phospho1 deficiency transiently modifies bone architecture yet produces consistent modification in osteocyte differentiation and vascular porosity with ageing. Bone 81:277-291. https://doi.org/10.1016/j.bone. 2015.07.035

26. MacRae VE, Davey MG, McTeir L et al (2010) Inhibition of PHOSPHO1 activity results in impaired skeletal mineralization during limb development of the chick. Bone 46:1146-1155. https://doi.org/10.1016/j.bone.2009.12.018
27. Roberts SJ, Stewart AJ, Sadler PJ, Farquharson C (2004) Human PHOSPHO1 exhibits high specific phosphoethanolamine and phosphocholine phosphatase activities. Biochem J 382:59-65. https://doi.org/10.1042/BJ20040511

28. Zhou B, Huang Y, Li H et al (2016) Proton-pump inhibitors and risk of fractures: an update meta-analysis. Osteoporos Int 27:339 347. https://doi.org/10.1007/s00198-015-3365-x

29. Sachs G, Shin JM, Hunt R (2010) Novel approaches to inhibition of gastric acid secretion. Curr Gastroenterol Rep 12:437-447

30. Mizunashi K, Furukawa Y, Katano K, Abe K (1993) Effect of omeprazole, an inhibitor of $\mathrm{H}+, \mathrm{K}+$-ATPase, on bone resorption in humans. Calcif Tissue Int 53:21-25. https://doi.org/10. 1007/BF01352010

31. Gagnemo-Persson R, Samuelsson A, Håkanson R, Persson $P$ (1997) Chicken parathyroid hormone gene expression in response to gastrin, omeprazole, ergocalciferol, and restricted food intake. Calcif Tissue Int 61:210-215. https://doi.org/10. 1007/s002239900325

32. Ciancaglini P, Yadav MC, Sper Simão AM et al (2009) Kinetic analysis of substrate utilization by native and TNAP-, NPP1or PHOSPHO1-deficient matrix vesicles. J Bone Miner Res 25:091029140456050-37. https://doi.org/10.1359/jbmr.091023

33. Yadav MC, Bottini M, Cory E et al (2016) Skeletal mineralization deficits and impaired biogenesis and function of chondrocyte-derived matrix vesicles in Phosphol I- $^{--}$and Phosphol/P t1 Double-Knockout Mice. J Bone Miner Res 31:1275-1286. https://doi.org/10.1002/jbmr.2790

34. Millán JL (2013) The role of phosphatases in the initiation of skeletal mineralization. Calcif Tissue Int 93:299-306. https:// doi.org/10.1007/s00223-012-9672-8

35. McKee MD, Yadav MC, Foster BL et al (2013) Compounded PHOSPHO1/ALPL deficiencies reduce dentin mineralization. J Dent Res 92:721-727. https://doi.org/10.1177/0022034513 490958

36. Cui L, Houston DA, Farquharson C, MacRae VE (2016) Characterisation of matrix vesicles in skeletal and soft tissue mineralisation. Bone 87:147-158

37. Costa-Rodrigues J, Reis S, Teixeira S et al (2013) Dose-dependent inhibitory effects of proton pump inhibitors on human osteoclastic and osteoblastic cell activity. FEBS J 280:5052-5064. https://doi.org/10.1111/febs.12478

38. Cui GL, Syversen U, Zhao CM et al (2001) Long-term omeprazole treatment suppresses body weight gain and bone mineralization in young male rats. Scand J Gastroenterol 36:1011-1015. https://doi.org/10.1080/003655201750422585

39. Yanagihara GR, de Paiva AG, Neto MP et al (2015) Effects of long-term administration of omeprazole on bone mineral density and the mechanical properties of the bone. Revista Brasileira de Ortopedia (English Edition) 50:232-238. https://doi. org/10.1016/j.rboe.2015.03.002

40. Anderson HC (2003) Matrix vesicles and calcification. Curr Rheumatol Rep 5:222-226

41. Robison R (1923) The Possible Significance of Hexosephosphoric Esters in Ossification. Biochem J 17:286-293. https:// doi.org/10.1042/bj0170286

42. Anderson HC, Sipe JB, Hessle L et al (2004) Impaired calcification around matrix vesicles of growth plate and bone in alkaline phosphatase-deficient mice. Am J Pathol 164:841-847. https:// doi.org/10.1016/S0002-9440(10)63172-0

43. Delomenède M, Buchet R, Mebarek S (2009) Lansoprazole is an uncompetitive inhibitor of tissue-nonspecific alkaline phosphatase. Acta Biochim Pol. https://doi.org/10.18388/abp.2009_ 2462 
44. Kirchheiner J, Glatt S, Fuhr U et al (2009) Relative potency of proton-pump inhibitors-Comparison of effects on intragastric pH. Eur J Clin Pharmacol 65:19-31

45. Graham DY, Tansel A (2018) Interchangeable use of proton pump inhibitors based on relative potency. Clin Gastroenterol
Hepatol 16:800-808.e7. https://doi.org/10.1016/j.cgh.2017.09. 033

Publisher's Note Springer Nature remains neutral with regard to jurisdictional claims in published maps and institutional affiliations. 